\title{
Social professionals in school: a comparative study
}

ABSTRACT

\author{
Ana Vieira \\ ESECS, CIID-IPL and CesNova \\ ana.vieira@ipleiria.pt
}

\begin{abstract}
School education is progressively becoming a social question and not only a matter of pedagogic nature. The increase of the diversity of the audience present in the school has brought forth policies and differentiating school responses which aim to build a "school for all". In this paper we seek to understand how the growing social tensions which are observed in the form of indiscipline at school are managed, whether towards other social professionals or only towards teachers. This paper presents a comparative study between three educational contexts which comprise socio-pedagogic mediation practices: Educational Context of Early Intervention (Território Educativo de Intervenção Prioritária - TEIP) and two Support Offices for Students and their Families (Gabinetes de Apoio ao Aluno e à Família - GAAF). In the three cases, there are senior social workers (técnicos superiores de trabalho social - TSTS), social educators, youth workers and social assistants who work with teachers on a daily basis. The research done in this paper focuses mainly on the teachers' opinion concerning the emergence of these new professions and their socio-pedagogic contribution in the school.
\end{abstract}

\section{Indexing terms/Keywords}

Socio-pedagogical Mediation, Senior Social Workers (TSTS), Educational Contexts.

\section{Academic Discipline And Sub-Disciplines}

Education; Social Education; Sociology;

\section{SUBJECT CLASSIFICATION}

Education

\section{TYPE (METHOD/APPROACH)}

Survey/Interview

\section{Council for Innovative Research}

Peer Review Research Publishing System

Journal: INTERNATIONAL JOURNAL OF RESEARCH IN EDUCATION METHODOLOGY

Vol 6, No.1

www.ijrem.com , ijremeditor@gmail.com 


\section{INTRODUCTION}

The democratisation of education in Portugal, after the revolution carried out on the 25th of April of 1974, the declaration of Salamanca (1994) which resulted from the meeting involving 92 governments and 25 international organizations in order to promote Education for All, and the consecutive reforms to the educational system in Portugal opened the school up to different social groups and various cultures, usually kept away from the school logic, thus increasing social tensions in educational contexts and making it necessary to find other types of responses which were less familiar to teachers. Teachers found themselves confronted with more questions of a social nature which went beyond the traditional role of educators. The school is one of society's microcosms and, as such, it is a place and a time for interaction between people of different ages, genders, cultures, languages and dialects, religions, knowledge, a place of encounters and of conflicts which fosters identification, (un)identification, passions and tensions, which are part of life, of human development and the mainspring of the transformation of the I and the we, of students and teachers. As a consequence, tension, indiscipline, conflict, social problems, etc. are an essential part of life and of life at school.

The teacher is quintessentially a mediator; at the very least a facilitator, an intermediary and a motivator between the student and knowledge (Cosme and Trindade, 2007). Hence, they bring the two parts, the student and knowledge, closer together, while working as a link in this encounter. A good pedagogic relationship is necessarily based on a good mediation relationship between the student, the teacher and knowledge. However, the teacher is often also a preventive mediator and someone who resolves tensions and conflicts which arise in the classroom and in the school in general (Vieira, 2013).

Mediation implies building a third place, as stated by Michel Serres in his book The Third Instructed (1993). This third place may be occupied by the same person who gives and receives information if they are able to play the role of the mediator, between point $A$ and point $B$, metaphorically speaking, when, for example, one finds themselves in distinct languages and cultures, different cognitive styles or different interaction contexts. Therefore, translation is an act of mediation. Mediation practices may be considered from two perspectives, one which involves more problem-solving and another which is more preventive, both of which probably result in many tasks for one individual teacher, as can be seen in the research presented below:

Hence, we have what may be called a conservative perspective - mediation as "social orthopaedics» (Correia and Caramelo, 2003: 173) - and a critical perspective - mediation as a promoter of social change. In the first case, we frequently find that social conflict can be reduced to a communication problem «the tendency to reduce social conflict to deficits of communication between individuals or between institutions is not absent from the reputation of mediation" (Correia and Caramelo, 2003: 178). In the case of the school-family correlation, for example, this perspective may base itself on the assumption that the cultural deficit of families who are from more rural environments and/or ethnic minorities, which causes mediation to produce a school-mirror effect (Silva, 2003) and, therefore, reproduce the social inequalities, in practice. On the other hand, the critical perspective may adopt an intercultural-like posture, thus promoting a bridge between cultures and more equal social relationships (Silva et al, 2010: 81).

Some teachers are able to fulfil the various social roles that the complexity of sociocultural and socio-pedagogic mediation implies (Vieira, 2013). Other teachers demand new professionals in the school to deal with the social issues and with community work, the students' family and sociocultural context, because they believe that these go beyond the scope of their functions.

This mediation perspective, extended from the school to the community/society, and vice versa (Almeida, 2010), has preceding examples, some of which are worth mentioning:

"Similar initiatives have occurred in all of France over the last few years. When the municipalities get involved, things can achieve a different dimension through multidisciplinary teams: teachers-educators-youth workers become essential elements in the fight for success in any school. Spurred on by an IDEN, a municipal councillor or a group of social assistants, the community tries to find solutions for the problems observed regarding some children" (Dannequin, 1989: 91). In this paper, we present the summary of a comparative study, carried out for a doctorate degree in the area of education and social pedagogy (Vieira, 2011), among three educational contexts in the district of Leiria which include socio-pedagogic mediation practices: one TEIP and two GAAF, one built from the bottom up, relying on the dedication of the teachers and the development of an educational project, and the other implemented from the top down, with the support of external institutions such as the Child Support Institute (Instituto de Apoio à Criança - IAC) where there are social educators, youth workers, socio-pedagogic mediators and social assistants, the TSTS, who work with the teachers on a daily basis regardless of there being a perfect harmony in relation to the educational project.

The growth of student diversity has fostered discussion on the school's functions. The inclusion movement has increasingly been mentioned in opinions given and in some educational practices, and it aims to integrate and promote the personal and academic success of all students. School has become "primarily a social, and not pedagogic problem or one which is pedagogic only to the extent that it is social" as stated by Carvalho and Baptista (2004). How should these new social tensions be dealt with in the school? With or without social educators, youth workers, mediators and other TSTS in the school? The teacher, however multifaceted they may be, is not always prepared for socio-pedagogic mediation and social work in the school, even though they may sometimes try to do so voluntarily. 


\section{THEORY AND METHODOLOGY}

In this research, the question is composed of objectives rather than of hypotheses which should be verified (Bell, 1997). Of course the hypotheses are always crucial, but here not in a positivist or verificationist manner with the intention of confirming, rebutting or rejecting them (Boavida and Amado, 2006; Guerra, 2006).

We did not move unknowingly from theory into practice, as is the case in classic ethnography (Caria, 2003), nor did we place ourselves on the opposite end with the a priori construction of hypotheses to be verified. The starting point, in this case, is the study of real situations in Portuguese schools in order to analyse the need for training and inclusion of sociopedagogic mediation professionals who can deal with conflict situations and/or those of exclusion which arise in the educational context. Whether there is room in the school for other social professionals other than teachers was always the guiding question in all of our research.

This research lies in the field of the Educational Sciences, in a socio-anthropological perspective, and aims to essentially deepen understanding, in the wake of Max Weber, while moving away from essentialist concepts. Nonetheless, it does also find support in percentages and other statistical data.

Within a complexity paradigm, in the manner of Edgar Morin, we avoided the methodological dualisms and chose to combine methods which make it possible to understand what is specific without losing sense of the global complexity. We carried out interviews which were initially open and free-flowing or unstructured and which slowly became in-depth interviews similar to "conversations", more with some individuals than with others, and ethnographic interviews (Spradlay, 1979; Vieira, 2003). Statements made by pedagogic managers, teachers and TSTS were gathered so as to understand how the new educational and social practices, whether they are potential, emerging or developing, are perceived by the different social actors. We carried out the document analysis of the educational projects of the three educational contexts being studied; field work with direct and participant observation and a survey using a questionnaire was conducted with teachers from the three educational contexts.

The fact that we aimed to observe the school from the inside led us to favour a descriptive, interpretive and comprehensive approach to reality, which implies that the researcher is assumed as an ethnographer who is able to capture the invisible side of the actors and the hidden or less visible side of the school (Woods, 1990.) We did not choose the quantitative/qualitative dichotomy, but rather sought the use of various tools in order to understand the complexity that Bourdieu designated as methodological polytheism (Bourdieu, 2005), in such a way that, here, limited by the need for synthesis, some are more evident than others.

\section{THE ANALYSIS AND DISCUSSION OF DATA: EDUCATIONAL CONTEXTS, SOCIAL ACTORS AND POINTS OF VIEW}

We now present the data and its discussion. A comparative analysis of three cases, 3 educational contexts studied in the center of Portugal is done, highlighting the common aspects between the three contexts studied and the limitations, advantages and disadvantages of including social workers in educational projects, featuring some cases of success and failure: the TEIP of Praia, the Social Work in the School Grouping of Calçada and the GAAF in Pinhal. The first case was in the Parish of Praia, the most populous parish in the municipality of Leiria where the educational project detected domestic violence, loneliness, the elderly's needs, lack of nursery schools, and lack of organization of leisure time for youngsters, alcoholism, drug addiction and unemployment as social problems.

The School Grouping of Calçada is located in the outskirts of the city and it provides for a large number of children of immigrants and of Romani people. In this case the social problems mentioned in the educational project are indiscipline, teenage pregnancy, and lack of social and parental competences of families.

The third case is located $12 \mathrm{Km}$ from the capital of the district of Leiria, in Pinhal, where the manufacturing industry is the main sector of the economic activity. Many students of this school live in areas considered problematic and come from dysfunctional families, where in some cases their parents are drug addicts.

With regard to the advantages and disadvantages of a school being TEIP, we systematized two approaches. Pedro Francisco, former chairman of the board of the school in Praia and promoter of school autonomy and of the TEIP 1, states, without hesitation that being a TEIP school only has advantages because it allows the access to material and human resources that are impossible to obtain any other way. The current headmaster of the school in Praia has the same viewpoint and ensured that, if there is another TEIP competition, the school grouping will apply again. On the contrary, the teacher Amândio, director of the School Grouping of Calçada who defends that teachers should have mediation skills, and who runs a school with a population similar to Praia, which shares the same stereotypes of the schools in the outskirts of the city, says that he prefers to accept the challenge to search for material and human resources to develop inclusion strategies, rather than apply for and receive funds because it has become a TEIP. He is aware of the negative stigma that both schools have and of how important it is to have a good image of a school, for which the label TEIP does not contribute (Canário, Alves and Rolo, 2001). 
The people of Calçada have a more critical opinion of the experience of the GAAF, which lasted a year, in comparison to the other two cases. This difference may be based on the fact that the experience of the GAAF was superficial, rapid and, partly, announced objectives to deal with the social strains that, in some way, had been idealized for some time, regarding the behavior workshop (oficina de comportamento - OC), which has been the mark of this educational context, at least in the school headquarters. The idea of the psychologist's work in the school, and of the social work done by them and the other teachers involved in the OC, implemented here 10 years ago in order to address family problems and to resolve conflicts in schools, was already common and was incorporated in many teachers' opinions, much before the GAAF appeared here.

This process has ascending dynamics, i.e. it moves from the bottom up, since it results from the will of the teachers belonging to the school. Despite having a better structure and with resources and financial support from a national structure, the Child Support Institute (Instituto de Apoio à Criança - IAC), the GAAF did not announce anything new and does not seem to have left any indication that the school would want to return to it. Here, mediation is considered to be a tool which should be used at the end of the line, in problem-solving, either by the behavior workshop, where students go whenever they are expelled from the classroom, or by those who take on the role of the psychologist, or even by those who take on the demanded role of the teacher as a behavior mediator, which the headmaster defends.

Regarding the School of Pinhal, its headmaster has been an important promoter of the GAAF and of the implementation of pedagogic innovations. Headmaster Carlos is, of the three headmasters, the one who is the most involved in the educational project which embraces a GAAF. He is also the one who has the most theoretical knowledge, which he expressed in long interview conversations (Bogdan \& Birklen, 1994):

"With this office, and with this multidisciplinary team, we are able to make more effective diagnoses... We are able to respond to indications given by the teachers, in many circumstances, for which they no longer had conditions to act upon. We are also able to have a set of activities and initiatives promoted by people in whom we have full confidence that they will carry them out, because they are exactly that: they are social workers, and as social workers we acknowledge their competence, and they are able to have the autonomy to promote activities which respond to the needs of those groups of young people. And so, in this perspective..., the school can only benefit, of course. The community can only benefit, of course".

From his point of view, not only did the school gain the ability to intervene in known situations but also at a diagnostic level. For him, the TSTS can screen for "disguised" situations, through home visits:

"On the other hand, there is also the visit made by these social workers to the families themselves... and trying to find situations which are sometimes disguised, and it is necessary to try to understand them... Therefore, from that point of view I think that the school gained not only the ability to intervene in situations we were aware of, but also diagnose others. Furthermore, the students themselves brought about great interaction with the office and with these social workers... and they felt that they were an answer. An answer which initially goes far beyond academic issues."

Headmaster Carlos, who is aware of the importance of the GAAF, along with the teachers, have sought alternative means of funding, other than the dependence on the IAC and the "choices" program, to support it. In his opinion, either one considers these projects and the TSTS's work as necessary or they do not. If they are, then it is necessary to find means to support them.

Let us now look at some of the subjects teachers agree and disagree upon with regard to socio-pedagogic mediation and the inclusion of TSTS in the school's educational projects, based on the questionnaire conducted and the interviews carried out in these three contexts.

Regarding the number of questionnaires distributed in each school and the number that were answered and became the universe, we first suggest the interpretation of the following table.

Table 1. Questionnaires distributed and answered in each Educational Context

\begin{tabular}{|c|c|c|c|}
\hline $\begin{array}{c}\text { Name of the } \\
\text { Questionnaire }\end{array}$ & $\begin{array}{c}\text { No. of } \\
\text { questionnaires } \\
\text { distributed }\end{array}$ & $\begin{array}{c}\text { No. and percentage of } \\
\text { questionnaires answered }\end{array}$ & $\begin{array}{c}\text { No. and percentage of } \\
\text { unanswered questionnaires }\end{array}$ \\
\hline TEIP of Praia & 120 & $89-74 \%$ & $31-26 \%$ \\
\hline GAAF - Calçada & 130 & $49-38 \%$ & $81-62 \%$ \\
\hline GAAF - Pinhal & 130 & $55-42 \%$ & $75-58 \%$ \\
\hline
\end{tabular}


The total number of questionnaires received was considered to be $100 \%$ but, in fact, they do not present the thoughts of many more teachers. As a sample, it is more convenient than representative. This difficulty in gathering data using a questionnaire conducted with teachers seems to show that, at the moment, these professionals are also burdened with an overload of administrative work.

The first part of the questionnaire, which we cannot deal with in this paper, aimed to generally characterize the teachers who answered the questionnaire conducted in the three Educational Contexts.

The second part of the questionnaire presented the teachers' characterization of their classes, namely regarding their heterogeneity and the practices which they carry out, as well as the demands of other social professionals in the school and the limitations which they feel on a daily basis. From this part, which was studied in depth in the research which led to the Ph. D thesis (Vieira, 2011), herein we only highlight the opinion of the teachers regarding TSTS in the school and the problems which they detect in school nowadays.

Concerning the question "do you believe it is possible to detect problems connected to the students' family life, in school?" in the three cases the answers are "yes", respectively: $100 \%$; $97.96 \%$ and $100 \%$. Similarly, with the question "are there students in your classes with social and family problems?", "yes" prevails at $93.26 \% ; 87.76 \%$ and $92.73 \%$. The most mentioned family problems in the three cases are the same and in the same order: broken families and economic difficulties.

Moreover, a significant number of teachers, in the three presented situations, say that they do not have time nor preparation to help the students when they detect a problem. Thus, they signal it $13.48 \% ; 20.24 \%$ and $23.24 \%$, respectively, when they claim that they do not have time or any type of preparation to help the students, when there is a problem. To sum up, a considerable percentage of the teachers admits not having theoretical or practical preparation to solve the social problems in school, which may indicate the wish to validate the work of other professionals, besides teachers, in the school. However, it is strange to see that $8.99 \% ; 6.12 \%$ and $7.27 \%$, respectively, accept to have preparation and time to help students. Even more important, bearing in mind the significance of the answers (in this case, of the non-answers), is the fact that in the three cases $94.38 \%, 77.56 \%$ and $76.36 \%$, respectively, of the teachers who had answered no to the question "in your daily practice do you worry about helping to solve students' social problems?" did not present any type of justification. They say they do not worry about helping to solve students' social problems, but they do not say why.

In the question "what do you do when you encounter a so-called "problematic» student?" it is interesting to note that in the first and second case, the most widely used strategies are: try to help the student $(87.64 \%$ and $85.71 \%)$. They focus on the student. The teacher concentrates on themselves and on the student. On the other hand, in the third case, the most widely used strategy is: speak to the class director. There seems to be a policy which involves referral to the class director who will then refer the student to specialized help, for example to the GAAF, if they deem this necessary. Here the strategy is of decentralization and of work done as a team or a network.

When teachers are asked for their opinion regarding the school's ability and resources to solve the students' social problems, the majority, in the three cases, states that the school does not have the necessary conditions to solve their students' social problems, respectively $87.64 \% ; 81.63 \%$ and $65.45 \%$. Only the percentages which range from $12.36 \%$ to $23.64 \%$ of the teachers questioned, depending on the schools, state that these have the necessary conditions to solve the various social problems which exist.

Some teachers believe that they are potential mediators and promoters for solving social problems, which does not happen when they think of the school as an institution. Some justifications regarding the school's inability to solve students' social problems are: "lack of specialized social workers in terms of number and time availability and of work in the school environment" (teacher from the School Grouping of Calçada), "the school needs more psychologists [...]. More Special Education teachers are needed" (teacher from the School Grouping of Praia) to justify the "yes": "in this school's particular case, through the GAAF it has a multidisciplinary team" (teacher from the Secondary School of Pinhal).

When asked "do you believe the GAAF/TEIP can be beneficial for success in the students' academic path?" the answer "yes" is unanimous in the three cases, $87.64 \%, 87.76 \%$ and $87.27 \%$, respectively. We have chosen some of the most representative answers in each case: 'Having identified the students' problems, this may provide students with other facilitating alternatives for success" (teacher from the School Grouping of Praia), "in helping to solve students' problems: in their intervention with parents and/or other social workers" (teacher from the School Grouping of Calçada), "sometimes students do not understand their negative behaviors and with this project [GAAF] they have been able to overcome these problems" (teacher from the Secondary School of Pinhal).

We can infer from the answers provided that the teachers accept and acknowledge the need for other specialized technicians in the school. In fact, regarding whether or not specialized professionals in the school to solve students problems were desired, we were able to note that all of the teachers enquired would like the school to have more professionalized staff to solve their students' social problems. With regards to the technicians which the teachers would like to have in the school, the psychologist, the social assistant, the socio-cultural educator and the socio-cultural youth worker were identified. The speech therapists and health technicians were also suggested. Moreover, the questionnaires show that the teachers know little about the student's other side, the family, the living conditions, etc., even though their characterization can be found in the class director's dossier. 
On a discursive note, the TSTS are considered to be teachers' teammates, but the truth of the matter is that their collaboration is very limited. Similarly to what happens in the ZEP, studied by Van Zanten (1990), we were also able to observe that in these three educational contexts there is no proximity in the work, neither in terms of planning, nor in terms of the implementation of projects. The two types of professionals inhabit two completely different worlds which have become impervious, regardless of what the two have in common: the students which interact with both.

For the teachers, the TSTS are specialists in screening, compensation and dialogue, in the interaction and treatment of problematic families. In the questionnaires conducted in the three contexts, the opinion that the TSTS are important in the school is clear. In the interviews, along with the teachers who reinforce this importance, others criticize the lack of networking between teachers, which they attribute to the way the GAAF has been implemented, as if they were not part of the operationalization of projects. Some even say that they are necessary as long as they do not interfere with the teachers' work, which would imply a delegation of tasks where no one would be held responsible.

The teachers' opinions on TSTS are vague (Zanten, 1990). Most teachers simply show concern about delineating each one's domains. On one hand, the TSTS define themselves as potential and effective socio-cultural and socio-pedagogic mediators with competences and functions that go far beyond what is acknowledged by teachers. They place emphasis mainly on their proximity to families, communities and the environment from which the students come, and claim that this knowledge is vital for educational success in mass schooling. On the other hand, the TSTS claim that it has taken a long time for teachers to explain their presence and function in the schools, despite the fact that they continue to be stereotyped.

Many TSTS believe teachers are incapable of changing the class environment and the interpersonal and intercultural relationship, which creates tension, as well as social and discipline problems in the school. They feel that they are viewed as "fire extinguishers", capable of solving the students' problems as if they were an objectified element in each daily behavior. The truth of the matter is that only collaboration between the teacher, who calls attention to the situation, and the TSTS, who seek a solution and who focus not only on the problem as a result of a specific social interaction but also on preventive mediation regarding conflicts, among other situations (Vieira and Vieira, 2011), may transform this supplementary work into integrated work, where the school brings together, on the same level, education and social work professionals and where education is always viewed as social education, regardless of it happening in classrooms, in the playground or at home, and encouraged by teachers and social work and social education technicians.

In the three school groupings, regarding the opinions, there seems to be no doubt that the TSTS are viewed as sociopedagogic mediators. Bearing in mind that the experiences are still quite recent in Portugal (although we know that the number of GAAF has already reached one hundred in the country, as have the TEIP) and that, since the Social School Work does not yet present a formal and delineated professional space in the school context, it can be said that new professionals are probably emerging and being recognised so that they may act within the school context, under an inductive logic, not imposed from top to bottom by ministries, legal diplomas, etc., but because of the acknowledgement of the TSTS's efficiency in practice.

These are projects which give schools a greater autonomy (TEIP) and which are only possible if there is solid financial autonomy (GAAF). In terms of end results, there are more similarities than differences between these three projects: the school seems to be more open to the community and, on the other hand, to the acceptance of new educational actors in the school, the TSTS.

In empirical terms, these are three cases, three Educational Contexts, where socio-pedagogic mediation explicitly exists. However, keeping to an ideology of pedagogic differentiation and cooperative learning, which exist in the TEIP, GAAF and OC projects, none of these three contexts can escape the patholization of difference (Vieira and Vieira, 2011), i.e., the idea that difference is a deficiency. This is immediately visible in the projects' design; however, it becomes even clearer in their operationalization, as well as in the opinions which the various social actors express, according to the interviews conducted.

\section{CONCLUSIONS}

Within the scope of the three educational contexts which were studied, the question "How do primary and secondary school teachers view the inclusion of TSTS in the school staff?", both the questionnaires presented and the interviews conducted clearly show that although teachers take on the role of learning and knowledge mediators, and even of sociopedagogic mediators, they welcome the integration of TSTS in the Educational Contexts, to work together on the development of each educational project, because they feel they do not have the skills to solve the social tensions and the problems related to students' family lives. Some answers to the questionnaires' open-ended questions (scarce because they were rarely answered) and interview statements allow us to believe that teachers consider many social dimensions to be natural, by reflecting on students that which is the result of their own social conditions, gained in a stigmatized manner and verbalized through the student-problem, family-problem, neighbourhood-problem and context-problem ideas, as well as other patholizations of difference (Barbieri, 2003; Canário, Alves and Rolo, 2001; Chaveau, 1989; Correia and Caramelo, 1994; Demazière, 2010; Vieira and Vieira, 2011; Zanten, 1990). We had the opportunity to work closely with the social workers, cultural and socio-pedagogic youth workers, social educators, among others, in the three educational contexts which were analysed. We were also able to note that if the TSTS are welcome by the teachers and if they are already in these schools where there are socio-pedagogic mediation offices, the truth is that there is no consensus regarding what they do and may still do there along with, and differently, in comparison to psychologists who have a longer history of working in schools. 
This research has also shown us that there is a significant number of teachers who, in light of being up-to-date professionals, accept the possibility of carrying out all of these tasks in relation to students, families and the community, without resorting to other internal professionals. When all of their own potential has been exploited, they prefer to invest in educational projects which, by building networks with other social institutions, may solve whatever teachers are unable to do themselves, whenever necessary. In addition, the research revealed how important it is for teachers to be part of the mediation teams in order to shorten the distance between the teacher/educator and the social worker/mediator and not to allow more isolated islands to appear in the educational context. These are three organizational spaces for sociopedagogic mediation, in three specific educational contexts, which resort to new professionals in academic education, the TSTS, and which, regardless of the type of mediation that they practise, be it more preventive or more directed towards conflict solving, are an asset for the school, for the communities to which these belong to and for a society which should be more inclusive.

\section{REFERENCES}

1. Almeida, V. 201). O Mediador sociocultural em contexto escolar - contributos para a compreensão da sua função social. Mangualde: Edições Pedago.

2. Barbieri, H. 2003. "Os TEIP, o projecto educativo e a emergência de 'perfis de território', Educação, Sociedade \& Culturas, 20. Porto: Edições Afrontamento, 43-75.

3. Bell, J. 1997. Como realizar um projecto de investigação. Lisboa: Gradiva.

4. Boavida, J.and Amado, J. 2006. Ciências da Educação: Epistemologia, Identidade e Perspectivas. Coimbra: Imprensa da Universidade de Coimbra.

5. Bogdan, R. and Biklen, S. 1994. Investigação qualitativa em educação: Uma introdução à teoria e aos métodos. Porto: Porto Editora.

6. Bourdieu, P. 2005. Esboço para uma Auto-análise. Lisboa: Edições 70.

7. Canário R.; Alves N. and Rolo, C. 2001. Escola e exclusão social. Lisboa: Educa.

8. Caria, T. (Org.) 2003. Experiência etnográfica em Ciências Sociais. Porto: Ed. Afrontamento.

9. Carvalho, A. and Baptista I. 2004. Educação Social. Fundamentos e estratégias. Porto: Porto Editora.

10. Chaveau, G. 1989. “L'échec scolaire au quotidien”, in Chaveau, Gérard and Duro-Courdesses, Lucile (Orgs.) (1989). École et quartiers. Paris: Editions L’Harmattan, 39-55.

11. Correia, J. and Caramelo, J. 1994. "Da Mediação Local ao Local da Mediação", Educação, Sociedade e Culturas, 20. Porto: Edições Afrontamento, 167-191.

12. Cosme, A. and Trindade R. 2007. “A Escola a Tempo Inteiro: Escola para que te quero?”, Porto: Profedições.

13. Dannequin, C. 1989. "Apprendre à l'école et autour de l'école", in Chaveau, Gérard e Duro-Courdesses, Lucile (Orgs.). École et quartiers. Paris: Editions L’Harmattan, 85-104.

14.Demazière, D. 2010. "A mediação social, um trabalho de terreno", in Correia, José Alberto and Silva, Ana Maria Costa. Mediação: (D)Os contextos e (D)Os Actores. Porto: Edições Afrontamento/ClIE, 103-118.

15. Guerra, I. 2006. Pesquisa qualitativa e análise de conteúdo. Estoril: Principia.

16. Serres, M. 1993. O Terceiro Instruído. Instituto Piaget: Lisboa.

17. Silva, P. et al 2010. "Mediação Sociopedagógica na Escola: conceitos e contextos", in Peres, A. and Vieira, R. (Orgs.). Educação, Justiça e Solidariedade na Construção da Paz. Chaves and Leiria: APAP and CIID-IPL, 75-99.

18. Spradley, J. 1979. The ethnographic interview. N.N.Y.: Prentice Hall.

19. Vieira, A. 2013. Educação Social e Mediação Sociocultural, Porto: Profedições.

20. Vieira, A. 2011. Educação e Mediação Sociocultural: a emergência de novos papéis sociais na escola, tese de doutoramento, Vila Real: UTAD.

21. Vieira, A. and Vieira R. 2011. "Territórios Educativos e Mecanismos de Lidar com a Diferença na Escola", Actas do II Encontro de Sociologia da FLUP - Educação, Territórios e Desigualdades. Porto: FLUP, 317-335.

22. Woods, P. 1990. L'Ethnographie de l'École. Paris: Armand Colin.

23.Zanten, H. A. 1990. L'Ecole et L'Espace Local. Les Enjeux des Zones d'Education Prioritaires. Lyon: Presses Universitaires de Lyon. 


\section{Author' biography}

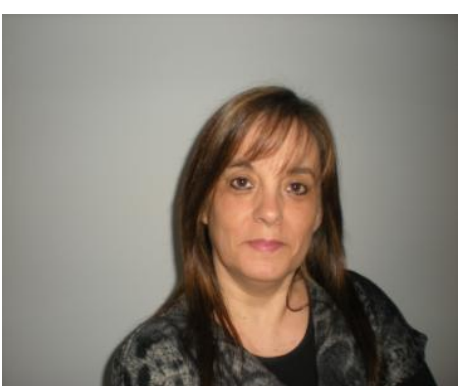

Ana Vieira was born in Coimbra in 1964. She is Master of Science in Education History and Current Problems of Education -, and PhD in Education, Social Education in the area of socio-pedagogical and Mediation. It is currently adjunct professor in the School of Education and Social Sciences (ESECS), Polytechnic Institute of Leiria (IPL) and researcher at the Center for Identity and Diversity Research (IDRC-IPL), core CesNova, Portugal.

His research focuses on intercultural mediation, social education, socio-pedagogical mediation, sociocultural mediation, social education, social work and indiscipline, areas where it has published in books, national and international magazines, and which has developed communications presented at national and international conferences. 